\title{
DOS RETRATOS PICTÓRICOS DE PABLO DE CÉSPEDES EN SEVILLA
}

\section{TWO PAINTED PORTRAITS OF PABLO DE CÉSPEDES IN SEVILLE}

\author{
Pedro M. Martínez Lara \\ Universidad de Sevilla. España \\ ORCID: 0000-0001-5056-2552 \\ pedrom@us.es
}

En el presente artículo se aborda el estudio razonado de dos pinturas conservadas actualmente en Sevilla y que contienen el retrato del pintor y humanista cordobés Pablo de Céspedes ${ }^{1}$. Este análisis pretende aportar nuevo conocimiento sobre el proceso creativo y la realidad material de ambas obras, prestando especial atención a las fuentes y modelos utilizados, y la significación de los mismos, contribuyendo así a reconstruir y facilitar la aproximación al medio en el que surgieron ambas. De igual modo, el estudio busca profundizar en el propósito y motivaciones con el que fueron pintadas.

Palabras clave: Pablo de Céspedes; Eduardo Cano; José Jiménez Aranda; pintura; Sevilla,

This paper approaches the reasoned study of two paintings preserved in Seville containing the portrait of Pablo de Céspedes, a Cordovan humanist and painter. This analysis aims to provide new knowledge about the creative process and both works physics reality with special attention to the models used and their significance. Similarly, the study seeks to delve into the purpose and motivations with which were painted.

Keywords: Pablo de Céspedes; Eduardo Cano; José Jiménez Aranda; painting; Seville.

\section{INTRODUCCIÓN}

El proceso creativo que tiene como resultado una obra de arte siempre ha estado condicionado por factores que no solo incluyen al genio creador del artista que la materializa. Esta génesis siempre tiene lugar en un medio contextual

${ }^{1}$ Sirva como testimonio de profunda gratitud, respeto, sincero homenaje y reconocimiento al profesor Dr. Vicente Lleó Cañal, a quien considero mi maestro. Primero inspirador y luego director de mi tesis doctoral titulada Pablo de Céspedes y los procesos de producción y asimilación entre Italia y España, entre el Renacimiento y el Barroco, defendida en el Departamento de Historia del Arte de la Universidad de Sevilla en 2012. 
concreto, en el que la obra aparece condicionada en sus aspectos formales y de significación por toda una serie de circunstancias. Los dos retratos que se presentan en este estudio no son, en modo alguno, obras fortuitas. Son el resultado de toda una serie de motivaciones y nacieron para cumplir unos propósitos determinados, que aún hoy siguen vigentes. Otro aspecto fundamental en este sentido es el propio proceso creativo de las formas, cuyo análisis resulta clave para la correcta comprensión de la obra.

El fin primordial del retrato es dejar constancia visual estable, a través de una imagen, de la realidad física de alguien. Más allá de ese empeño primario, que debe considerarse inherente al género y de otras cuestiones teóricas y técnicas, como el formato o el parecido que debe guardar con el modelo, que serán abordadas de manera pormenorizada más adelante, es conveniente realizar una aproximación a lo que supone el retrato de un personaje considerado ilustre o virtuoso y el empeño que encierra, bien de forma aislada o formando serie con otras piezas similares.

Es en el Renacimiento italiano cuando el Humanismo recupera el concepto clásico de las galerías de uomini virtuosi, práctica que se extendería por Europa materializadas en colecciones de medallas ${ }^{2}$, libros de retratos ${ }^{3}$ y series de pinturas.

La presentación de retratos que perpetúen el recuerdo visual y moral de determinados personajes célebres cumple una triple misión. En primer lugar, servir de exempla y edificación para quienes las contemplaban. Cuestión que manifiesta la misiva que el humanista nuremburgués Hieronymus Münzer dirigió a en 1493 a su compatriota Hartmann Schedel, con quien preparaba el Liber chronicarum $^{4}$. En ella defiende los retratos de los ilustres y la necesidad de incluirlos en la obra, puesto que estas imágenes "son tan útiles para los ignorantes e iletrados como los son los escritos para los doctos", estimulando a quien las ve a "seguir la huella

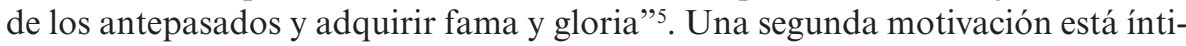
mamente relacionada con la mentalidad humanística, puesto que, a través de los

${ }^{2}$ La medalla se había convertido en el "vehículo favorito para inmortalizar a los grandes hombres". Su materialidad física permitía un coleccionismo casi sin límites de espacio a la vez que la doble faz de estas piezas posibilitaba representar por un lado la verdad física del personaje mientras que, por el otro, bien con inscripciones, bien con complejos emblemas, se significaba la verdad espiritual y moral. LLEÓ CAÑAL, Vicente: Nueva Roma. Mitología y Humanismo en el Renacimiento sevillano. Sevilla, 1979, p. 54.

${ }_{3}^{3}$ Por la comodidad que representaba y tras el desarrollo de la imprenta, los libros de retratos grabados con sus correspondientes elogios también fueron frecuentes. Una buena aproximación a estos se encuentra en BURKE, Peter: "La sociología del retrato renacentista", en El retrato en el Museo del Prado. Madrid, 1994, pp. 114-115.

${ }^{4}$ SCHEDEL, Hartmann: Liber chronicarum. Núremberg, 1493.

5 FLETCHER, Jennifer: "El retrato renacentista: funciones, uso y exhibición", en $E l$ retrato del Renacimiento. Madrid, 2008, p. 77; y BAXANDALL, Michael: The Limewood Sculptors of Renaissance Germany. New Haven, 1980, pp. 8 y 225. 
retratos y la admiración de estos, sus protagonistas podían alcanzar una suerte de vida eterna a través de la perpetuación de su fama en la memoria de las generaciones sucesivas. Fama que era obtenida destacando en virtudes y ejemplaridad en vida. Aunque la inclusión en una serie de retratos, también infundía virtud a quien no la tuviera, lo que podía suponer un formidable atajo para la inmortalidad. Una tercera motivación consistía en que estas series de retratos podían proporcionar a sus poseedores cierta legitimación y cualificación en el presente, haciendo que el prestigio y virtudes de los antepasados fueran los cimientos de su fama y consideración. Claro ejemplo de ello es la serie de retratos de hombres ilustres que el marqués de Tarifa encargó entre 1537 y 1539 a los pintores Alonso Hernández Jurado y Diego Rodríguez para su nuevo palacio sevillano en la collación de San Esteban. Una serie que, como ya documentó Lleó, incluía tanto personajes del pasado como Creso, Cicerón, Horacio, Tito Livio y otros, así como árboles genealógicos de la familia Enríquez -hoy desaparecidos- en los que se justificaba el origen hercúleo, ergo mítico, de su linaje ${ }^{6}$. Fadrique Enríquez materializa así, y de forma muy temprana, estos ideales humanistas en Sevilla sentando un clarísimo precedente de la realización, siglos más tarde, de los dos retratos que son objeto de este trabajo, ambos incluidos en sendas series pictóricas de hombres ilustres inspiradas en los citados ideales. La primera fue realizada por Eduardo Cano de la Peña para el salón de sesiones de la Real Academia de Bellas Artes de Santa Isabel de Hungría de Sevilla (Figura 1). La segunda, obra de José Jiménez Aranda, forma hoy parte de la colección de retratos de personalidades ilustres de la Biblioteca Capitular y Colombina de Sevilla (Figura 2).

La presencia de artistas entre los elogiados en estas galerías de virtuosos es constante desde el Renacimiento. Se trata de una cuestión lógica, ya que el ideal humanista establecía que quienes se dedicaban al ejercicio de las artes plásticas, lo debían hacer como uomini virtuosi, es decir, como intelectuales. Paulo Giovio puede ser considerado uno de los pioneros en esta cuestión al incluir a León Battista Alberti en la galería de retratos de su museo a orillas del lago de $\mathrm{Como}^{8}$, así como en el libro que recogía estas efigies y sus correspondientes elogios ${ }^{9}$. Con el

${ }^{6}$ LLEÓ CAÑAL, Vicente: Nueva Roma..., op. cit., p. 55. Sobre la historia del palacio y su decoración artística la obra más actualizada es la de LLEÓ CAÑAL, Vicente: La Casa de Pilatos: biografía de un palacio sevillano. Sevilla, 2017.

7 Uno de los estudios más completos es el de AGOSTI, Barbara: Paolo Giovio. Uno storico lombardo nella cultura artistica del Cinquecento. Florencia, 2008.

${ }^{8}$ GIANONCELli, Matteo: L'antico Museo di Paolo Giovio in Borgovico. Como, 1977; y SUÁREZ QUEVEDO, Diego: "Los Hvomini Famosi de Paolo Giovio. Alberti en el primer Museo", Anales de Historia del Arte, 20, 2010, pp. 87-123.

${ }^{9}$ La primera edición, en lengua latina, no estuvo ilustrada, pero sí la publicada en Basilea en 1575 ya fallecido su autor, que incorporaba grabados xilográficos. GIOVIO, Paulo: Elogia veris clarorum virorum imagginibus apposita quae in Musaeo Ioviano Comi spentantur: addita in calce operis Adriani Pont. Vita. Venecia, 1546; y GIOVIO, Paolo: Elogia 
tiempo, aparecerían obras y series pictóricas dedicadas en exclusiva a artistas, siendo la más significativa Le Vite, redactada por Giorgio Vasari ${ }^{10}$, personaje especialmente ligado a Giovio.

El caso de Pablo de Céspedes (Córdoba, ca. 1542-1608) no es convencional. No se trata de un simple pintor. Antes al contrario, este ilustre eclesiástico ${ }^{11}$, literato y coleccionista ${ }^{12}$ cordobés debe ser considerado uno de los mejores exponentes del humanismo hispano ${ }^{13}$. La del racionero es una personalidad clave no solo por su pintura e influencia artística en lo plástico, sino también y aún más por sus escritos, que abarcan desde la historia erudita a la teoría del arte, estando algunos de ellos redactados en verso ${ }^{14}$. Estos méritos, la amistad y sobre todo la potente impronta e influencia que causó Céspedes en Francisco Pacheco, le valió el figurar retratado y elogiado en su Libro de verdaderos retratos ${ }^{15}$, así como

virorum literis illustrium, quotquot vel nostra vel auorum memoriam vixere. Ex eiusdem $\mathrm{Mu}$ saeo ad viuum expressis imaginibus exornata. Basilea, 1575.

${ }^{10}$ VASARI, Giorgio. Le vite de piu eccellenti architetti, pittori, et scultori italiani, da Cimabue insino a' tempi nostri. Florencia, 1550.

${ }^{11}$ MARTÍNEZ LARA, Pedro M.: "Novedades documentales en torno a Pablo de Céspedes. El expediente de limpieza de sangre", Historia, Instituciones, Documentos, 38, 2011, pp. 291-323.

12 MARTÍNEZ LARA, Pedro M.: "Sedimento material de una vida humanista. El inventario de bienes de Pablo Céspedes", Boletín de Arte, 32-33, 2012, pp. 437-455.

${ }^{13}$ La primera gran monografía es la de TUBINO, Francisco María: Pablo de Céspedes. Madrid, 1868. Sin embargo la bibliografía más actualizada se encuentra en RUBIO LAPAZ, Jesús: Pablo de Céspedes y su círculo. Humanismo y contrarreforma en la cultura andaluza del Renacimiento al Barroco. Granada, 1993; DÍAZ CAYEROS, Patricia: "Pablo de Céspedes entre Italia y España", Anales del Instituto de Investigaciones Estéticas, 75, 2000, pp. 5-60; y REDÍN MICHAUS, Gonzalo: Pedro Rubiales, Gaspar Becerra y los pintores españoles en Roma, 1527-1600. Madrid, 2007, pp. 266-271.

${ }^{14}$ RUBIO LAPAZ, Jesús y MORENO CUADRO, Fernando: Escritos de Pablo de Céspedes. Edición crítica. Córdoba, 1998; JAQUERO ESPARCIA, Alejandro: "Pablo de Céspedes como paradigma del clasicismo pictórico en el Siglo de las Luces: la influencia en Diego Antonio Rejón de Silva y su poema La Pintura”, en Las artes de un espacio y un tiempo: el setecientos borbónico. Madrid, 2015, pp. 405-426; y JAQUERO ESPARCIA, Alejandro: "La teoría de la pintura versificada en la Edad Moderna: de Pablo de Céspedes a Diego Antonio Rejón de Silva”, en La formación artística: creadores-historiadores-espectadores. Santander, 2018, pp. 1323-1333.

${ }^{15} \mathrm{El}$ libro original fue reproducido de forma facsímil y publicado a finales del siglo XIX. PACHECO, Francisco: Libro de descripción de verdaderos Retratos, de Ilustres y Memorables varones. (Manuscrito original reproducido en foto-cromo-typia por la Librería Española y Extranjera de D. Rafael Tarascó, s.a.). Sevilla, ca. 1880. Para su conocimiento, resultan imprescindibles la introducción del profesor Bassegoda al Arte de la Pintura y la monografía de la profesora Cacho. PACHECO, Francisco: El Arte de la Pintura, ed., intr. y notas de Bonaventura Bassegoda y Hugas. Madrid, 2001, pp. 11-50; y CACHO CASAL, Marta P.: Francisco Pacheco y su Libro de retratos. Madrid, 2011. 
posteriormente en la mayoría de los repertorios de vidas de $\operatorname{artistas}^{16}$, algunos de los cuales preveían estar ilustrados con su imagen, aunque jamás salieron publicados de ese modo. Existe una nada despreciable historiografía en relación a una serie de dibujos que contienen el retrato de Pablo de Céspedes, alguno de los cuales ha sido relacionado con los libros de vidas de artistas y personajes ilustres ya citados $^{17}$. Una efigie, la de Céspedes elaborada por Pacheco, que tendrá también una trascendencia determinante en la génesis de las dos obras que aquí se tratan.

\section{EL RETRATO DE PABLO DE CÉSPEDES POR EDUARDO CANO}

El 31 de octubre de 1849 la reina Isabel II firma en Madrid un Real Decreto que reorganizaba los establecimientos de enseñanza y academias de bellas artes de todo el reino ${ }^{18}$. Por el mismo, la vieja Real Escuela de las Tres Nobles Artes, que desde 1843 había pasado a ser la Real Academia de Nobles Artes de Santa Isabe $^{19}$, adquiría un nuevo estatus y denominación: Real Academia de Bellas Artes de primera clase de Sevilla ${ }^{20}$. En aquel momento y desde el final de la invasión francesa, la institución tenía establecida su sede y actividad en el extinto convento agustino de San Acacio en la calle Sierpes ${ }^{21}$. Poco tiempo después se verifica el traslado de la Academia al edificio del Museo Provincial de Pinturas, establecido

${ }^{16}$ Los más importantes de estos elencos en los que Céspedes forma parte son los de DE BUTRÓN, Juan: Discursos apologéticos en que se defiende la ingenuidad del arte de la pintura; que es liberal, y noble de todos los derechos. Madrid, 1626, f. 98v; BAGLIONE, Giovanni: Le vite de' pittori scultori et architetti. Dal pontificato di Gregorio 13. del 1572. In fino a' tempi di Papa Vrbano Ottauo nel 1642. Scritte da Gio. Baglione Romano e dedicate all'Eminentissimo, e Reuerendissimo principe Girolamo Card. Colonna. Roma, 1642, p. 30; PALOMINO DE CASTRO Y VELASCO, Antonio: El Parnaso español pintoresco laureado. Tomo. III, con las vidas de los pintores, y estatuarios eminentes españoles. Madrid, 1724, pp. 272-274; y CEÁN BERMÚDEZ, Juan Agustín: Diccionario histórico de los más ilustres profesores de las bellas artes en España. T. I. Madrid, 1800, pp. 316-325.

${ }^{17}$ Los trabajos más actualizados al respecto son los de Priscilla Muller y Benito Navarrete. MULLER, Priscila E.: Dibujos Españoles en la Hispanic Society of America. Del Siglo de Oro a Goya. Madrid, 2006, pp. 39-42, cat. 5; NAVARRETE PRIETO, Benito: "El triunfo del dibujo español en la Galería de los Uffizi”, en I Segni nel tempo. Dibujos españoles de los Uffizi. Madrid, 2016; y NAVARRETE PRIETO, Benito: "Un nuevo dibujo de Francisco Pacheco para su libro de retratos: La efigie de Pablo de Céspedes en los Uffizi", Archivo Español de Arte, 353, 2016, pp. 77-84.

${ }^{18}$ El Real Decreto fue publicado en la Gaceta de Madrid, n 5577, de 11 de noviembre de 1849, pp. 1-3.

19 MURO OREJÓN, Antonio: Apuntes para la historia de la Academia de Bellas Artes de Sevilla. Sevilla, 1961, p. 58.

${ }^{20}$ Ibidem, pp. 67 y 93.

${ }^{21}$ DE BESA RODRÍGUEZ, Rafael: "Localización de las distintas sedes de la Academia de las Tres Nobles Artes de Sevilla”, Temas de Estética y Arte, 28, 2015, pp. 193-ss. 
en el desamortizado convento casa grande de la Merced Calzada. Concretamente, entre el 6 de febrero de 1850 y el 11 de septiembre de ese año se produce el traslado a la nueva sede ${ }^{22}$. La Academia podría disponer ahora de espacios más dignos para el desarrollo de su actividad. Surgiría entonces la necesidad de ennoblecerlos para manifestar así el prestigio de la institución. Prueba de ello es la propuesta que realiza Manuel Carvajal, consiliario de la Academia, en la sesión del 7 de marzo de 1851, de decorar la sala de juntas "con los retratos de Murillo, Luis de Vargas, Velázquez y de pintores de la Escuela Sevillana"23.

La idea de que la decoración de la sala de sesiones de la Academia se centrara en los retratos de los que se consideraban pintores ilustres de la escuela sevillana enlaza claramente y en primera instancia, con lo expuesto acerca de las galerías de uomini virtuosi. Pero no es el humanismo la única referencia. El origen de la institución que ahora se quería rodear de los rostros de los maestros del arte sevillano, está en la Real Escuela puesta en marcha por Francisco de Bruna en 1775, sobre lo que quedaba de la Academia de Murillo, un grupo de artistas que mantenían un humilde centro de formación de las bellas artes ${ }^{24}$. Fue Bruna, destacado ilustrado y protector de la institución, quien en su oración dictada durante la junta de distribución de premios de 1778, realizó un encendido alegato poniendo a "los grandes ejemplos del pasado como referentes a la pintura del presente" ${ }^{25}$. Se trataba entonces de señalar la orientación hacia el buen gusto según los presupuestos ilustrados y se invitaba así a los artistas a emular a sus gloriosos predecesores.

${ }^{22}$ MURO OREJÓN, Antonio: Apuntes..., op. cit., p. 96 y n. I.

23 ARABASIH (Archivo de la Real Academia de Bellas Artes de Santa Isabel de Hungría de Sevilla), L. 48, Libro $2^{\circ}$ de actas (1845-1852), sesión de 7-3-1851, s. f. Muro Orejón fue el primero en dar a conocer esta moción, aunque con una fecha diferente a la que figura en la documentación. Más tarde, Rafael de Besa en su tesis doctoral se ha ocupado de todo el proceso de elaboración de la serie pictórica. MURO OREJÓN, Antonio: Apuntes..., op. cit., p. 96; y DE BESA RODRÍGUEZ, Rafael: La Academia y su Museo. criterios académicos en la gestión de los fondos del Museo de Bellas Artes de Sevilla. Tesis Doctoral inédita, Sevilla, 2016, pp. 357-362. Ejemplar disponible en https://idus.us.es/ xmlui/handle/11441/45146 (Consultado el 28-10-2018).

${ }^{24}$ MURO OREJÓN, Antonio: Apuntes..., op. cit., p. 3. Sobre la Academia de Murillo: CORZO SÁNCHEZ, Ramón: La Academia del Arte de la Pintura de Sevilla: 16601674. Sevilla, 2009; y GARCÍA BAEZA, Antonio: Entre el obrador y la academia: la enseñanza de las artes en Sevilla durante la segunda mitad del Seiscientos. Sevilla, 2014. Sobre Francisco de Bruna como protector de la Real Escuela: CABEZAS GARCÍA, Álvaro: Gusto orientado y fiesta pública en Sevilla. Análisis de documentos para la comprensión de la historia artística del siglo XVIII. Sevilla, 2012, pp. 26-ss.

${ }_{25}$ CABEZAS GARCÍA, Álvaro: Gusto orientado..., op. cit., p. 41. La transcripción de la oración celebrada el 14 de julio de 1778, en el Real Alcázar, donde tenía su sede, se encuentra a partir de la p. 49. 
En la aludida sesión académica del 7 de marzo de 1851, se ordenó convocar a los miembros de la sección de pintura para que resolvieran lo que fuere conveniente sobre el acuerdo tomado ${ }^{26}$. Dicha junta tuvo lugar el 10 de ese mismo mes ${ }^{27}$ y en ella se estableció un primer reparto de los retratos que cada profesor debía realizar. No obstante, Joaquín Domínguez Bécquer intervino y "manifestó que cifrándose la gloria de las artes en honrar la memoria de aquellos profesores que han inmortalizado sus nombres con sus obras, ya en pintura ya en escultura, creía corto el número de retratos" 28 . Así, la propuesta inicial de que la serie de retratos la integrasen las efigies de Luis de Vargas, Diego Velázquez y Bartolomé Esteban Murillo, fue ampliada la lista incluyendo a los pintores Juan de Roelas, Francisco de Herrera el Viejo, Francisco Pacheco, Francisco de Zurbarán y Alonso Cano, así como a los escultores Juan Martínez Montañés y Pedro Roldán. Es interesante el resultado de la selección, de la que no constan las deliberaciones, que sin duda habrían aportado aspectos clave de la consideración que estos académicos tenían de sus predecesores en el ejercicio del arte. Sí queda registrado que, aunque el propósito era representar artistas sevillanos, se incluyeron a Zurbarán y a Alonso Cano excusando que pese a que no eran naturales de Sevilla, sí se habían formado y desarrollado en ella ${ }^{29}$. De igual modo, se aprobó el formato y detalles que tendrían las pinturas ${ }^{30}$.

Al trasladarse los acuerdos de esta junta, para su refrendo en la sesión general del 13 de marzo, Antonio Cabral manifestó el interés de uno de sus hijos en participar en la realización de la serie de retratos. Acto seguido, se acordaba dar conocimiento del acuerdo a Eduardo Cano, ausente en aquella reunión, por si era de su agrado participar ${ }^{31}$.

Eduardo Cano de la Peña (Madrid, 1823-Sevilla, 1897) se formó en Sevilla adonde llegó siendo niño al ser nombrado su padre, Melchor Cano, arquitecto mayor de la ciudad ${ }^{32}$. Con 25 años, en noviembre de 1848, es incorporado como

26 ARABASIH, L. 48. Libro $2^{\circ}$ de actas (1845-1852), sesión de 7-3-1851, s. f.

${ }^{27} \mathrm{El}$ acta de la junta de la sección de pintura ARABASIH, L. 55, Libro de actas de la sección de pintura (1850-1897), ff. 1v-2r, se incorporó más tarde en el acta correspondiente a la sesión general del 13 de marzo. ARABASIH, Libro $2^{\circ}$ de actas, sesión de 13-31851 , s. f.

${ }_{28}$ ARABASIH, L. 55, Libro de actas de la sección de pintura (1850-1897), f. 1v.

${ }_{29}$ Ibidem, ff. 1v-2r. Hoy se sabe por el contrario que en ese elenco hay otros no sevillanos como Francisco Pacheco (Sanlúcar de Barrameda), Juan Martínez Montañés (Alcalá la Real) o Juan de Roelas (Flandes).

${ }^{30}$ Ibid., f. 2 r.

31 Ibid.

${ }^{32}$ El conocimiento actualizado y sistematización moderna de la obra de Eduardo Cano se deben fundamentalmente a la labor de investigación y estudios del profesor Pérez Calero, quien tras su monografía ha seguido publicando diversos trabajos sobre la vida y obra del pintor. PÉREZ CALERO, Gerardo: "Eduardo Cano. Pintor romántico", en El arte del siglo 
profesor a la Academia y un mes antes había sido nombrado académico honorario en reconocimiento a sus aptitudes ${ }^{33}$. Como consecuencia del R.D. de 31 de octubre de 1849, Cano fue considerado académico nato de la de Bellas Artes de primera clase $\mathrm{e}^{34}$. Gracias a que era conocido en el ambiente académico desde su ingreso como estudiante a la temprana edad de 12 años y a sus destacadas cualidades artísticas, Eduardo Cano gozó siempre de una alta consideración como pintor, primero entre sus profesores y más tarde entre sus colegas. Académicos sevillanos, que de alguna manera eran conscientes de que tenían ante sí a la que estaba llamada a ser una de las personalidades más relevantes de todo el panorama pictórico sevillano de la segunda mitad del siglo. Quizá esta circunstancia operó a favor de que los académicos no quisieran dejar de informar a Cano del proyecto de realización de la serie pictórica de los maestros de escuela sevillana.

En efecto, el acuerdo de la sesión del 13 de marzo sobre este respecto se materializó en un oficio con fecha 4 de julio de 1851, la cual no ha sido aún localizada pero de la que se conserva el acuse de recibo que Eduardo Cano giró a la Academia desde Madrid, el 10 de ese mismo mes $^{35}$. En la misiva, que fue comunicada a la Academia en la sesión del 14 de julio ${ }^{36}$, el pintor acepta la invitación a pintar el retrato de uno de los "Célebres pintores cuyas obras existen en esa ciudad" 37 , y manifiesta que realizará el del "célebre pintor y poeta Pablo de Céspedes" 38 . Poco más de cuatro meses después, se recibe en la Academia un nuevo mensaje de Eduardo Cano, fechado en Madrid el 18 de noviembre de 1851 y que con el anterior han permanecido inéditos hasta ahora, en el que el pintor declara haber

XIX: II Congreso Español de Historia del Arte. Valladolid, 1978, pp. 151-153; PÉREZ CALERO, Gerardo: El pintor Eduardo Cano de la Peña (1823-1897). Sevilla, 1979; y PÉREZ CALERO, Gerardo: "Eduardo Cano y Mariano Fortuny", Archivo Español de Arte, 236, 1986, pp. 418-419. Es también interesante la consulta de DEL RÍO LLABONA, Armando: "La técnica pictórica de Eduardo Cano", Boletín de Bellas Artes, 25, 1997, pp. 31-42; y DE LA BANDA Y VARGAS, Antonio: "Eduardo Cano, docente y académico de Bellas Artes", Boletín de Bellas Artes, 25, 1997, pp. 43-53.

${ }^{33}$ PÉREZ CALERO, Gerardo: El pintor..., op. cit., p. 14.

${ }^{34}$ El nombramiento se recoge en una Real Orden el 13 de febrero de 1850. Ibidem, p. 15.

${ }^{35}$ El contenido del billete que se conserva en el ARABASIH, leg. 69, Correspondencia de la Academia y sus dependencias 1850-1855, Carta de Eduardo Cano a la Academia sobre la realización del retrato de Pablo de Céspedes, exp. s. n.

${ }^{36}$ PÉREZ CALERO, Gerardo: El pintor..., op. cit., p. 16.

37 ARABASIH, leg. 69, Correspondencia de la Academia y sus dependencias 18501855, Carta de Eduardo Cano a la Academia sobre la realización del retrato de Pablo de Céspedes, exp. s. n.

38 Ibidem. 
realizado el retrato de Céspedes, el cual ha enmarcado y enviado a la institución sevillana, asumiendo el coste posta ${ }^{39}$.

Eduardo Cano se encontraba en Madrid en estos años iniciales de la Real Academia de Bellas Artes de primera clase, al haberse producido el fallecimiento de su madre y verse obligado a atender necesidades familiares. De forma paralela, se matriculó y asistió a clases en la Real Academia de San Fernando, bajo el magisterio de los pintores Carlos Ribera y Federico Madrazo ${ }^{40}$.

Si bien es muy significativo el proceso por el cual Cano quedó incluido en el programa pictórico ideado por uno de sus maestros sevillanos, Antonio Cabral Bejarano, para la realización de los retratos de los artistas sevillanos que habían de decorar y ennoblecer el nuevo salón de sesiones de la Academia, todavía es más interesante profundizar en las motivaciones que llevaron a Eduardo Cano a elegir retratar a Pablo de Céspedes. De un lado, parece claro que, al haberse repartido los académicos presentes en la junta de la sección, la realización de los retratos de los artistas más sobresalientes y afamados, Cano sería consciente de que su elección ya estaba limitada. Por otra parte, la lectura del acuse de recibo fechado en Madrid el 10 de julio de 1851, permite elucidar que era Cano quien escogía el personaje retratado, no tratándose por tanto de una designación proveniente de Sevilla. No obstante, no queda claro si, aparte de informarle de aquellos artistas ya adjudicados, los académicos sevillanos le proporcionaban una terna de la que escoger al personaje que sería objeto de su retrato, o bien se trató de una elección completamente libre. Quizá recibiese alguna influencia en este sentido por parte del entorno académico madrileño donde se hallaba inserto, pero se trata de algo que por el momento debe quedar en el terreno de la especulación. Mediada o no por el ambiente capitalino, el bien conocido perfil intelectual de Eduardo Cano permite afirmar que la elección de Pablo de Céspedes no fue en ningún caso fortuita. Antes al contrario, posibilita diversos análisis y lecturas interpretativas con arreglo tanto a la significación de la personalidad del racionero cordobés y la visión que de él se tenía a mediados del siglo XIX, como desde el punto de vista meramente formal con respecto al modelo físico del que partir para la realización del retrato. Una respuesta a la primera cuestión se encuentra en el ya aludido acuse de recibo, donde Cano expresa la elección, refiriéndose al cordobés como "pintor y poeta", lo que incluye de manera significativa la dimensión intelectual, culta, erudita del cordobés. Sobre todo, si se trataba de dar ejemplo con su efigie a los académicos que contemplasen su retrato, entrando así en consonancia con los ya aludidos presupuestos humanistas del Quinientos y también ilustrados del siglo XVIII enunciados por Francisco de Bruna. De hecho, el retrato de Céspedes

39 ARABASIH, leg. 69, Correspondencia de la Academia y sus dependencias 18501855. Carta de Eduardo Cano a la Academia con acuse de envío del retrato de Pablo de Céspedes, exp. s. n.

${ }^{40}$ PÉREZ CALERO, Gerardo: El pintor..., op. cit., p. 15. 
incluye, además de la consabida orla marmórea y la inscripción, la base del cuadro ocupada por un bodegón donde aparece la cartela con la firma del autor, un busto de mármol, la paleta de pintor con los pinceles introducidos por el hueco de la misma, papel para bocetos, libros abiertos y cerrados, un tintero con dos plumas y una lira, en alusión a la actividad plástica, literaria y poética de Céspedes.

Con respecto a la cuestión formal es muy importante señalar que el retrato de Pablo de Céspedes fue el primero de la serie en ser entregado. Pese a que los académicos sevillanos tuvieron conocimiento desde el mes de marzo de 1851 de sus encargos, parece claro que Cano actuó con diligencia, teniendo la pintura lista en poco más de cuatro meses, mientras otros demorarían años en entregar sus retra$\operatorname{tos}^{41}$. Es igualmente llamativo que pese a que el aludido bodegón que figura en la base del retrato de Pablo de Céspedes no es una de las condiciones contenidas en el acuerdo inicial, el retrato de Murillo, pintado por Antonio Cabral Bejarano y entregado algo más de un mes después que el de Céspedes ${ }^{42}$, incorpora este recurso, quizá influido por el cuadro pintado por Eduardo Cano.

Volviendo a la cuestión formal y centrando la atención definitivamente en el modelo utilizado para la realización del retrato de Pablo de Céspedes, ese es precisamente el problema al que aludieron otros maestros como justificación de la demora en entregar los retratos a los que se habían comprometido ${ }^{43}$. Aunque actualmente se conocen al menos dos retratos de Pablo de Céspedes, realizados por Francisco Pacheco y tomados del vivo ${ }^{44}$, en 1851 no se conocía ninguno de ellos ${ }^{45}$,

${ }^{41}$ Los cuadros serían instalados en el salón de sesiones a partir de 1853. Las fechas de los cuadros y la identidad de los retratados fueron proporcionadas por Muro. Más recientemente, toda la peripecia ha sido recogida y resumida por Rafael de Besa en su tesis doctoral inédita. DE BESA RODRÍGUEZ, Rafael: La Academia y su Museo..., op. cit., pp. 357-360.

${ }^{42}$ El retrato de Pablo de Céspedes llegaría a la Academia a finales del mes de noviembre de 1851, siendo certificada su llegada el 6 de diciembre de 1851, cuando el de Murillo fue recepcionado oficialmente en el acta del 4 de enero de 1852. ARABASIH, lib. 48, Libro $2^{\circ}$ de actas (1845-1852), sesión del 6-12-1851, s. f., y sesión del 4-1-1852, s. f.

${ }^{43}$ Es especialmente significativo el de Joaquín Domínguez Bécquer, quien abandonó por ese motivo la realización del retrato de Luis de Vargas. DE BESA RODRÍGUEZ, Rafael: La Academia y su Museo..., op. cit., p. 359.

${ }^{44}$ El primero es el que figura en el Libro de verdaderos retratos, mientras que el segundo es el que se conserva en la Gallería degli Uffizi, dado a conocer por Benito Navarrete. PACHECO, Francisco: Libro de verdaderos..., op. cit., p. 35; y NAVARRETE PRIETO, Benito: "Un nuevo dibujo...", op. cit. Este último ha formado parte de la exposición sobre dibujos españoles en los Uffizi comisariada por el profesor Navarrete. NAVARRETE PRIETO, Benito: "Pablo de Céspedes" (Ficha de catálogo), en I Segni nel tempo. Dibujos españoles de los Uffizi. Madrid, 2016, pp. 310-311, cat. 182.

${ }^{45}$ El manuscrito considerado original de Pacheco que hoy conserva la Fundación Lázaro Galdiano se encontraba en poder del médico Vicente Avilés desde al menos 1820 y allí fue conocido por un reducido grupo de personas entre los que se encuentran William 
ni tampoco parece que Cano tuviera constancia de las diferentes copias y versiones que los mismos se realizaron a lo largo del tiempo ${ }^{46}$. Hipótesis que aparece reforzada por el poco parecido que presenta el Céspedes de Cano con los que aparecen en los referidos dibujos. Cabe aquí establecer una elucubración desde el punto de vista teórico, y es que Cano estuviera atento a presupuestos que el propio Céspedes había manifestado sobre el parecido que los retratos han de tener con el modelo y que recoge Pacheco en el Arte de la Pintura ${ }^{47}$. En efecto, el tratado del sanluqueño recoge, a propósito del parecido que han de guardar los retratos con su modelo, que Céspedes defendía que era preferible realizar "una cabeza valiente" a que se pareciera al retratado, primando así la belleza y calidad de la obra frente a la verdad que debía haber en ella. Estuviera Eduardo Cano al tanto de esta cuestión o no, parece que no fue para él un obstáculo el no disponer de la efigie de Céspedes como sí lo habría de ser para alguno de sus colegas sevillanos. No obstante, una posible fuente para Eduardo Cano podría ser el dibujo y posterior grabado realizado en 1759 por Antonio Espinosa de los Monteros (Figuras 3-4), que se conservan en la Biblioteca Nacional. La estampa había alcanzado cierta difusión sobre todo en el ámbito de la Academia de San Fernando y su fisonomía es la que más se acerca al modelo usado por Cano. Estampa que fue copiada en dibujo en 1791 por José Maea y después grabada por Tomás López Enguídanos, para ilustrar el epítome de la vida de Pablo de Céspedes en el más importante y casi único libro de retratos y elogios de personalidades hispanas de todo el periodo ilustrado: Retratos de los españoles ilustres ${ }^{48}$, proyecto impulsado por el conde de Floridablanca y Diego Antonio Rejón de Silva, responsable de la gestión de las academias en la Secretaría de Estado. Una obra esta que sin duda conoció Eduardo Cano.

Stirling-Maxwell. ASENSIO Y TOLEDO, José María: Francisco Pacheco: sus obras artísticas y literarias especialmente el Libro de descripción de verdaderos retratos de ilustres y memorables varones, que dejó inédito: apuntes que podrán servir de introducción a este libro si alguna vez llega á publicarse. Sevilla, 1876; y MULLER, Priscilla E.: Dibujos españoles..., op. cit., pp. 69-70.

${ }^{46}$ MULLER, Priscila E.: Dibujos Españoles..., op. cit., pp. 80-83, cat. 16; y NAVARRETE PRIETO, Benito: “Un nuevo dibujo...”, op. cit. En este último trabajo se presentan ordenados coherentemente todos los conocidos hasta el momento.

47 PACHECO, Francisco: El Arte..., op. cit., p. 525; y CACHO CASAL, Marta P.: Francisco Pacheco..., op. cit., pp. 277-ss.

${ }^{48}$ Retratos de los españoles ilustres con un epítome de sus vidas. Madrid, 1791. El retrato y epítome de Pablo de Céspedes, cuya autoría se desconoce, se encuentran en páginas sin numerar entre los de fray José de Sigüenza y Diego de Covarrubias. Un reciente estudio se ocupa del proceso de producción de esta magna obra. MOLINA, Álvaro: "Retratos de españoles ilustres con un epítome de sus vidas orígenes y gestación de una empresa ilustrada", Archivo Español de Arte, 353, 2016, pp. 43-60. 


\section{EL RETRATO DE PABLO DE CÉSPEDES POR JOSÉ JIMÉNEZ ARANDA}

La Institución Colombina gestiona aparte de un incalculable tesoro documental y bibliográfico, una interesante colección de pinturas, especialmente retratos de personajes ilustres relacionados con la catedral de Sevilla y su arzobispado. Aunque se han registrado algunos intentos, y que en la actualidad están en marcha diversos proyectos de investigación orientados a ello, aún es un conjunto de pinturas por estudiar en profundidad. Parece que la colección se ha ido formando por aluvión sin que las pinturas guarden una unidad de formato, más allá de series facticias establecidas a partir de similitudes formales. Uno de estos retratos, considerado inédito en lo visual, es el del eclesiástico, humanista, literato y artista cordobés Pablo de Céspedes (Figura 2). Realizado al óleo sobre lienzo, es un tondo de $83 \mathrm{~cm}$ de diámetro y firmado "J. Jiménez", lo que permite adscribirlo al quehacer del pintor sevillano José Jiménez Aranda (Sevilla, 1837-1903) ${ }^{49}$. Se trata del más destacado de los discípulos de Eduardo Cano, autor del otro retrato de Pablo de Céspedes que centra este estudio.

La primera noticia de la existencia de esta pintura la proporciona Collantes de Terán en $1887^{50}$, quien enumera todos los retratos que alberga la institución, colocando el de Pablo de Céspedes en una serie de retratos, todos ellos de formato circular, que representan a "hijos célebres de Andalucía" y que se compone de trece ejemplares, refiriendo del de Céspedes: "Tomado del libro de retratos que ejecutó Francisco Pacheco y posee nuestro amigo el Exmo. Sr. D. José María Asensio y Toledo" ". Queda claro, aunque el simple análisis de la obra permite esta conclusión, que el retrato está tomado, en este caso sí, a partir de la que se considera una de las verdaderas efigies que se conservan de Pablo de Céspedes y que Asensio había adquirido, junto con el resto del Libro de verdaderos retratos en $1864^{52}$. Se trata en efecto de una versión muy fidedigna del dibujo original

${ }^{49}$ Nuevamente se debe a la labor investigadora del profesor Pérez Calero, a quien agradezco las indicaciones con respecto a este retrato de Pablo de Céspedes, la mayor parte del conocimiento sistemático de la vida y obra de este autor, comenzando por su ya clásica monografía de la colección Arte Hispalense a la que han seguido no pocos artículos y trabajos. PÉREZ CALERO, Gerardo: José Jiménez Aranda (1837-1903). Sevilla, 1982.

50 COLLANTES DE TERÁN, Francisco: "Galería de retratos de sevillanos ilustres que se conservan en la biblioteca del Exmo. e Ilmo. Cabildo, donde se ha concedido preferencia al del Almirante y descubridor del Nuevo Mundo D. Cristóbal Colón, por su alto renombre y por la circunstancia de conservarse en ella la famosa librería de su hijo D. Fernando, que dio a la Biblioteca el nombre de Colombina”, Archivo Hispalense, 3, 1887, pp. $169-176$ y $234-241$.

${ }^{51}$ Ibidem, p. 241.

${ }^{52}$ ASENSIO Y TOLEDO, José María: Francisco Pacheco: sus obras artísticas y literarias especialmente el Libro de descripción de verdaderos retratos de ilustres y memorables 
de Pacheco, si bien interpretado con la pincelada ágil y suelta de su autor, José Jiménez Aranda, cuya firma, "J. Jiménez", aparece en el retrato. En efecto, el pintor sevillano firmó de este modo en su juventud, como así lo demuestran algunas obras datadas desde sus comienzos hasta su primer viaje a Roma ${ }^{53}$. Por lo que respecta a la cronología, Pérez Calero ubica el cuadro alrededor de 1880 cerrando el denominado "periodo sevillano" entre la estancia del pintor en Valencia y el viaje a París ${ }^{54}$. No obstante, el modo de firmar no concuerda con estos años ya maduros del pintor. Una referencia indirecta ha permitido acotar la cronología de la pintura situándola unos diez años antes. En el excepcional trabajo recopilatorio de documentos realizados por don Juan Guillén, quien fuera bibliotecario de la Colombina, editado de forma póstuma ${ }^{55}$, se recoge un informe fechado el 12 de febrero de 1875, relativo a la devolución al cabildo de la biblioteca, tras haber sido incautada por el gobierno revolucionario en $1869^{56}$. En este informe se hacen referencia a diferentes "mejoras", esto es, diferencias, que los responsables del cabildo registraban tras volver a tomar posesión de la biblioteca, anotando: "Cuatro retratos de los sevillanos célebres: el marqués de Mina, don Pablo de Céspedes, Juan de Arfe y don José Diez" "57. Guillén apunta en referencia a estas pinturas, la existencia de una carta fechada el 28 de abril de 1870 en la que el bibliotecario agradece a D. Manuel Cabral Bejarano por haber pintado y regalado estos retratos" $" 58$. Aunque la carta no ha podido ser localizada, durante la investigación preparatoria de este estudio ha aparecido en el archivo de la Biblioteca Capitular un papel suelto que contiene algunos datos sobre la sala y estanterías de la institución donde también se hace referencia a la carta de agradecimiento a Cabral Bejarano, pero solo en relación a los retratos de Antonio Cabral Bejarano y Juan de Arfe. En el mismo documento, aparece la siguiente anotación "Pablo de Céspedes por D. José Jiménez, tomado del libro de Pacheco" ${ }^{59}$. La referencia

varones, que dejó inédito: apuntes que podrán servir de introducción a este libro si alguna vez llega á publicarse. Sevilla, 1867. En esta obra el autor relata toda la historia del manuscrito y de cómo fue adquirido.

${ }^{53}$ Existe un cuaderno juvenil de dibujos y otras pinturas de género costumbrista firmadas como J. Jiménez, que han sido estudiadas y publicadas por el profesor Pérez Calero. PÉREZ CALERO, Gerardo: "Un álbum juvenil de dibujos del pintor José Jiménez Aranda", Laboratorio de Arte, 19, 2006, pp. 349-368; y PÉREZ CALERO, Gerardo: "Una obra juvenil inédita del pintor José Jiménez Aranda”, Laboratorio de Arte, 23, 2011, pp. 617-619.

${ }^{54}$ PÉREZ CALERO, Gerardo: José Jiménez..., op. cit., p. 34.

${ }^{55}$ GUILLÉN, Juan: Historia de las Bibliotecas Capitular y Colombina. Sevilla, 2006.

${ }^{56}$ Ibidem, pp. 406 y 418.

57 Ibid., p. 418.

${ }^{58}$ Ibid., p. 425, n. 107.

59 BCC (Biblioteca Capitular y Colombina), papeles no catalogados. Agradezco sinceramente a Nuria Casquete, Isabel González y Nuria Prado la implicación y orientaciones para localizar esta referencia. 
permite establecer una cronología más coherente para la pintura, puesto que si en febrero de 1875 el retrato de Céspedes ya se encontraba en la Colombina, Jiménez Aranda solo pudo pintarlo entre enero de $1869^{60}$, fecha de la incautación de la biblioteca, y finales de 1871, cuando el pintor marcha a Roma ${ }^{61}$, concordando ahora sí la fecha con el formato de la firma.

En definitiva, se trata de dos retratos de Pablo de Céspedes que cumplen el noble propósito de incluir al racionero cordobés entre el selecto grupo de los ilustres sevillanos entre los que siempre se halló cómodo en vida. En el primer caso como exempla y para infundir virtudes en los académicos de las bellas artes, en el segundo para los estudiosos y eruditos que cultivan la historia y las letras en la Institución Colombina.

“¡Dichoso quien, como él, puede en la moderación y el retiro cultivar los buenos estudios, aventajarse en las artes, ser admirado y querido de su siglo, y dexar á la posteridad una memoria respetable!" ${ }^{2}$.

Fecha de recepción: 29 de octubre de 2018

Fecha de aceptación: 1 de julio de 2019

${ }^{60}$ GUILLÉN, Juan: Historia..., op. cit., p. 406.

${ }^{61}$ PÉREZ CALERO, Gerardo: José Jiménez..., op. cit., p. 24.

${ }^{62}$ Con esta exclamación, que ahora quisiera dedicar al profesor Vicente Lleó, a quien se homenajea en este trabajo, se remata el anónimo epítome de Pablo de Céspedes en los Retratos de los españoles ilustres..., op. cit., s. p. 


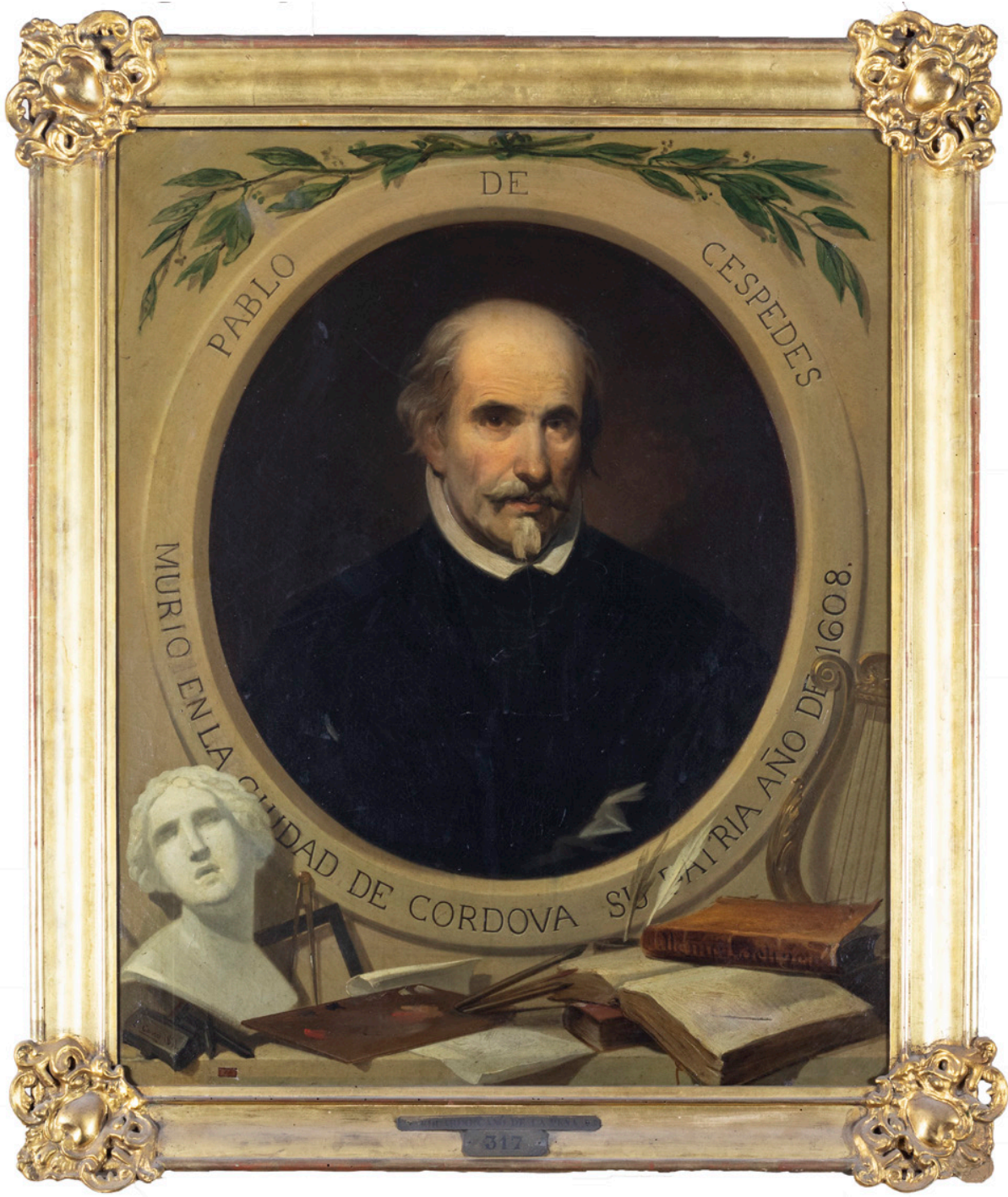

Figura 1. Eduardo Cano de la Peña, Retrato de Pablo de Céspedes, 1851, Real Academia de Bellas Artes de Santa Isabel de Hungría de Sevilla. Foto: Pedro M. Martínez Lara. 


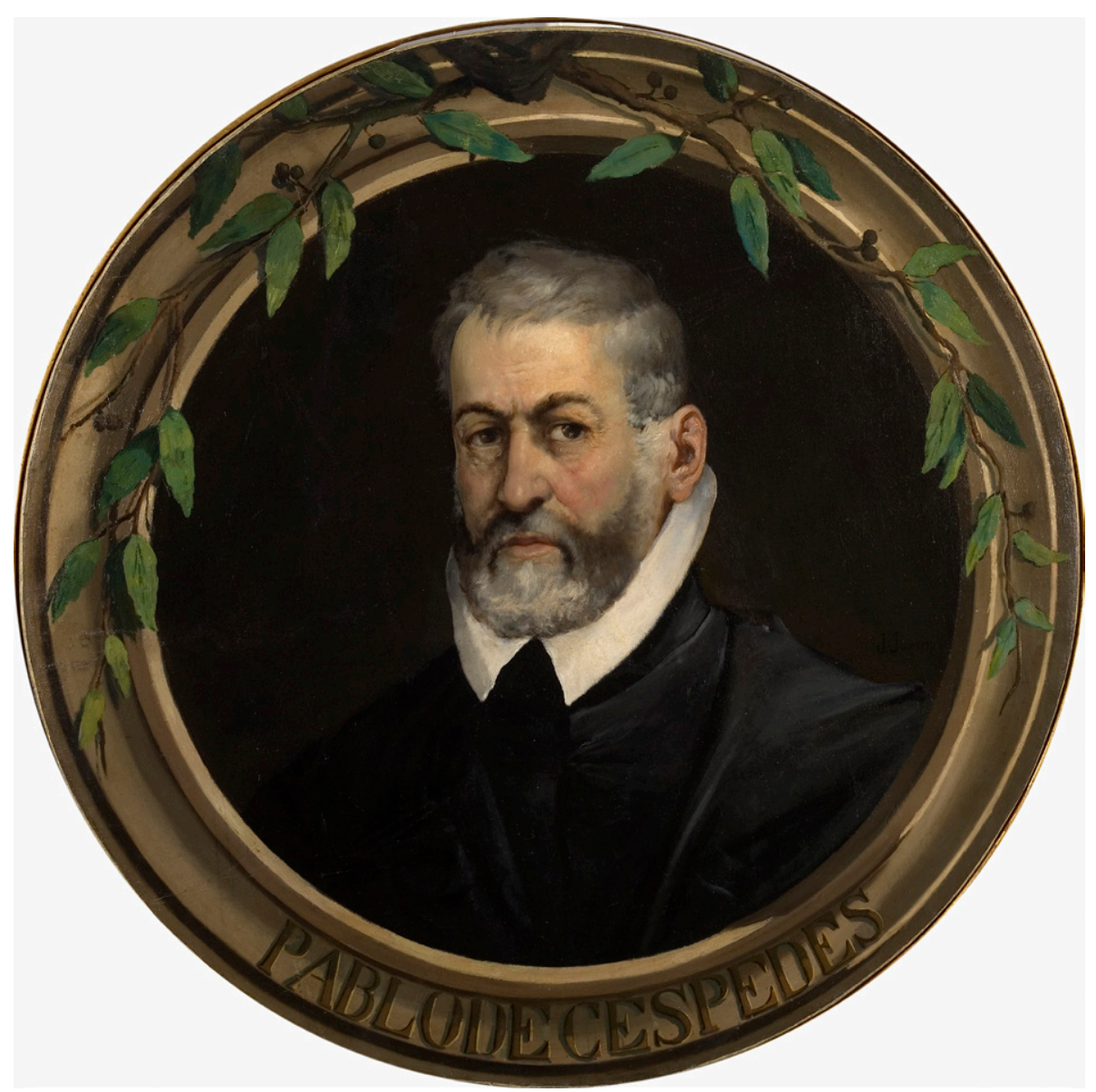

Figura 2. José Jiménez Aranda, Retrato de Pablo de Céspedes, 1869-1871, Biblioteca Capitular Colombina. Foto: Luis Serrano. 


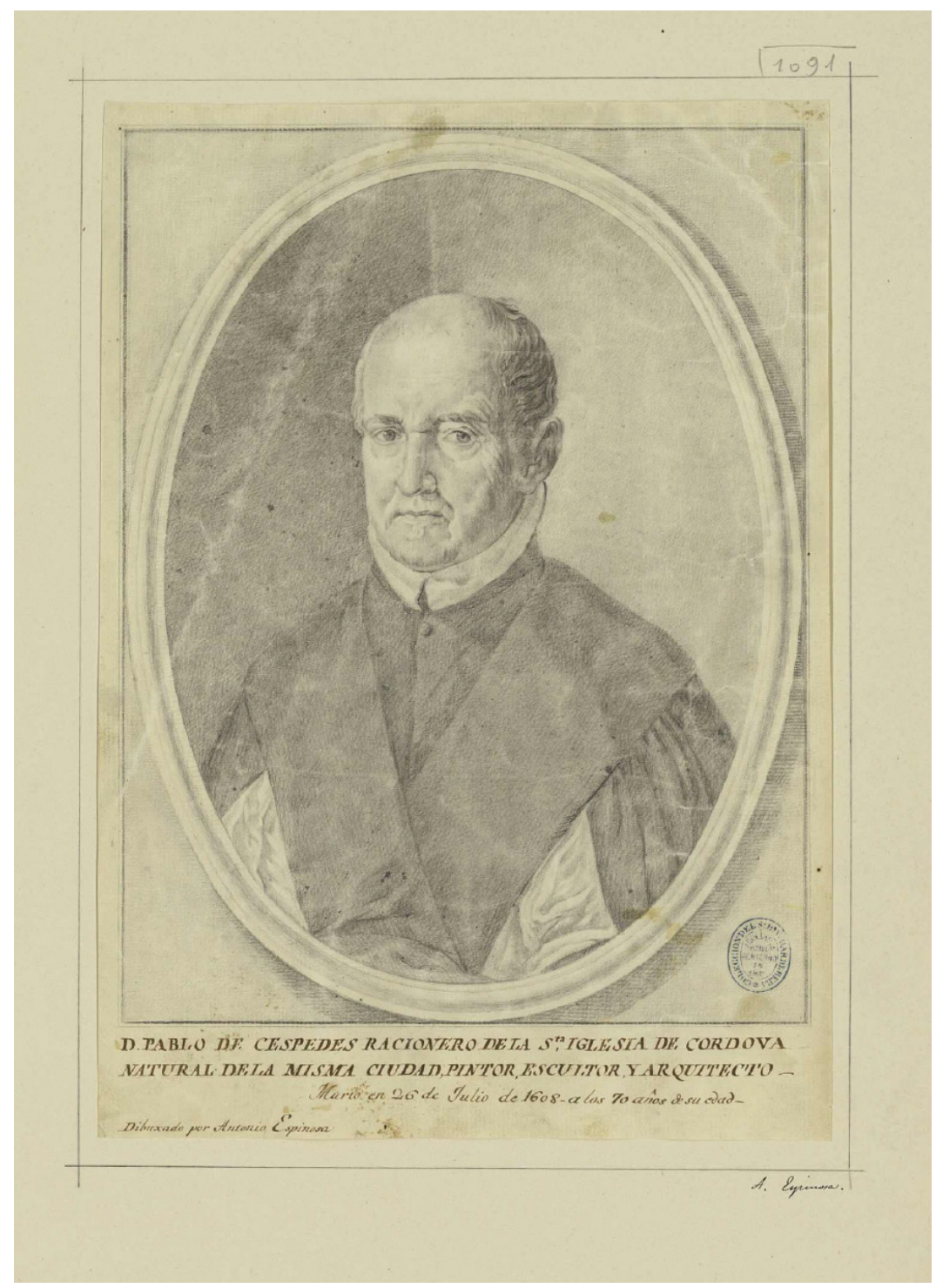

Figura 3. Antonio Espinosa de los Monteros, Retrato de Pablo de Céspedes, 1759, Biblioteca Nacional de España. DIB/15/29/21.

Foto: Biblioteca Nacional de España. 


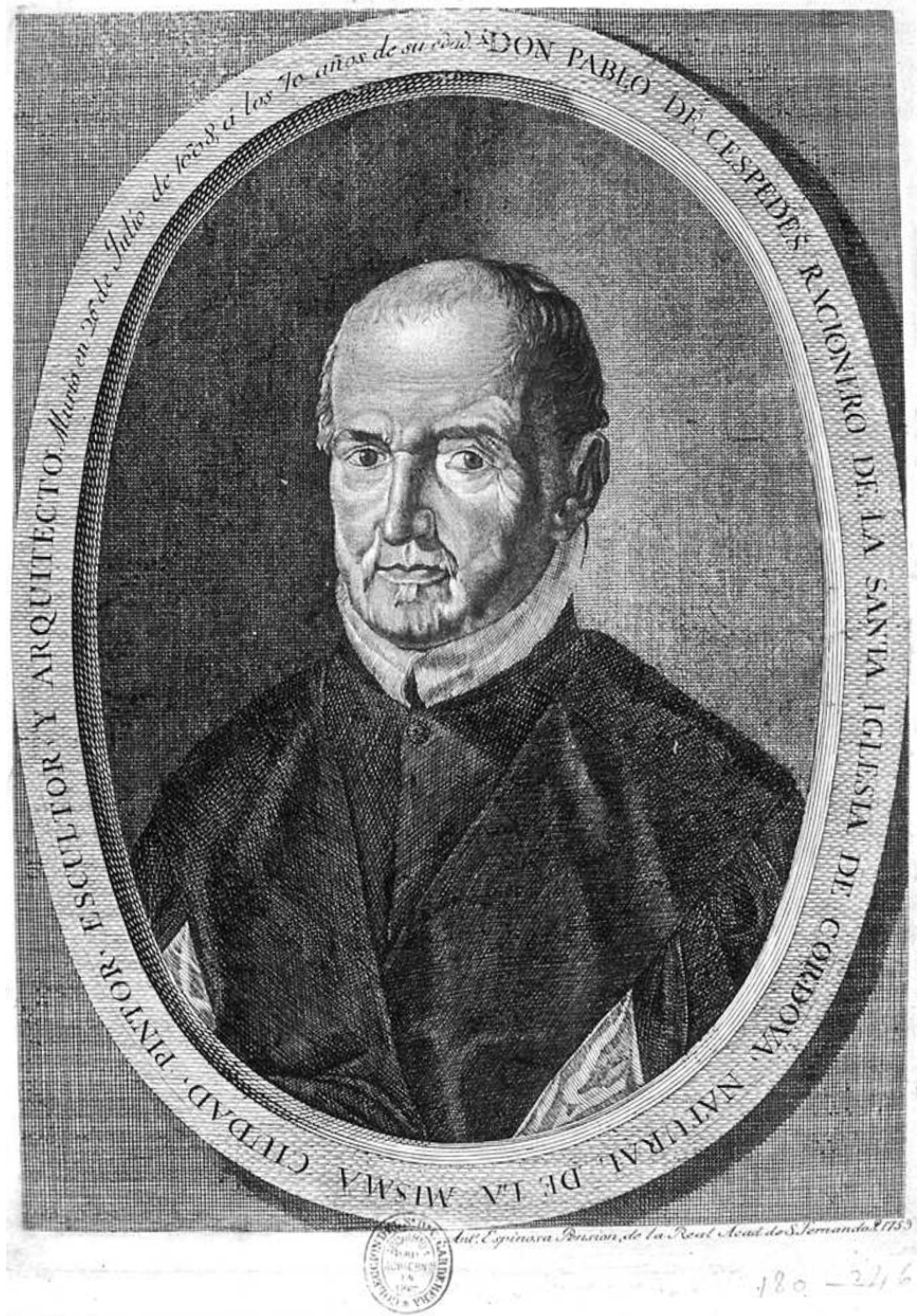

Figura 4. Antonio Espinosa de los Monteros, Retrato de Pablo de Céspedes, 1759, Biblioteca Nacional de España. Foto: Biblioteca Nacional de España. 